\title{
Thymic stromal lymphopoietin in hepatitis $C$ virus-related cryoglobulinemic vasculitis: gene expression level and protein distribution
}

\author{
Domenico Sansonno $^{1 *}$, Sabino Russi ${ }^{1}$, Silvia Sansonno $^{2}$, Fabio Pavone ${ }^{1}$ and Franco Dammacco ${ }^{1}$
}

\begin{abstract}
Introduction: Hepatitis C virus (HCV) infection can be detected in virtually all patients with cryoglobulinemic vasculitis (CV). Among its many effects, the virus is able to stimulate the production of thymic stromal lymphopoietin (TSLP) by infected hepatocytes. In this study, we assessed the systemic levels and tissue distribution of TSLP in 60 chronically HCV-infected patients, 36 with and 24 without CV.
\end{abstract}

Methods: Serum TSLP levels were measured by an enzyme-linked immunosorbent assay (ELISA) method. TSLP mRNA was assessed in patient samples by real-time reverse transcriptase-polymerase chain reaction (RT-PCR). TSLP protein in liver and skin biopsy samples was revealed by indirect immunofluorescence. All other methods were carried out according to standardized procedures.

Results: Serum TSLP levels were significantly higher in patients with than in those without CV and in healthy individuals. Higher TSLP levels paralleled specific mRNA expression and the up-regulation of TSLP protein in liver tissue. Compared with non-CV patients, higher TSLP levels in CV were accompanied by a higher frequency of circulating mono/oligoclonal B-cell expansions ( $8 \%$ vs. 92\%, $\mathrm{p}<0.0001)$ and a higher number of peripheral CD20 $\mathrm{B}$-cells $(10.3 \%$ vs. $15.5 \% \mathrm{p}=0.04)$. In addition, TSLP mRNA expression in the liver of CV patients was lower than in their correspondent skin tissue and paralleled specific immune deposits of TSLP protein in keratinocytes.

Conclusion: Overall, this study shows that TSLP secreted by hepatocytes and keratinocytes of HCV-infected patients with CV is involved in the pathogenesis of vasculitis and may possibly support the therapeutic use of TSLP-targeted monoclonal antibodies.

\section{Introduction}

Thymic stromal lymphopoietin (TSLP) is a four-helixbundle cytokine and a member of the common $\gamma$-chain cytokines, which are able to induce dendritic cells (DCs) and to stimulate naïve T-cell differentiation into T-helper 2 [1] and T-helper 17 [2] cells. TSLP binding and signaling occur by means of a heterodimer composed of the interleukin-7 receptor $\alpha$-chain and the TSLP receptor [3].

TSLP is a potent modulator of systemic B-cell development and is capable of promoting humoral autoimmunity. In the skin of a genetically engineered mouse, TSLP released into the systemic circulation by Notch-deficient keratinocytes induced a remarkable

\footnotetext{
* Correspondence: domenicoettore.sansonno@uniba.it

1 Liver Unit, Department of Biomedical Sciences and Human Oncology, University of Bari Medical School, 11 Piazza G. Cesare, 70124 Bari, Italy Full list of author information is available at the end of the article
}

expansion of peripheral pre-B cells and immature B lymphocytes, resulting in B-lymphoproliferative disorders and death [4]. In addition, local expression of TSLP under the control of a tetracycline-regulated, skin-specific promoter caused a substantial increase in bone marrow B lymphocytes and an earlier exodus of immature cells to the periphery [5]. These changes led to an increase in antibody-secreting cells, the production of mixed cryoglobulins, immune-complexmediated renal damage [6], and systemic inflammatory injury, an overall picture closely resembling human cryoglobulinemic vasculitis (CV) [7].

In the Mediterranean basin, over $90 \%$ of $\mathrm{CV}$ patients are chronically infected with hepatitis $\mathrm{C}$ virus (HCV), thus emphasizing the role of this virus in the pathogenesis of cryoglobulin production. However, only a subset of HCVpositive individuals develops mixed cryoglobulins and only 
a minority of these patients has clinically overt CV [8]. Bcell clonal expansions in the circulation and in the liver microenvironment are peculiar features of the humoral immune response of $\mathrm{CV}$ patients [9]. In addition, dominant B-cell clonalities probably contribute to the formation of intraportal follicle-like structures in the liver [10]. Analysis of the immunoglobulin heavy chain complementarity-determining region CDR-3, whether from circulating or tissue-derived B-cell-expanded clones, showed several variations in this immunoglobulin gene segment, supporting the notion that these cells are the result of an antigen-driven response [11]. Restriction in the use of the $\mathrm{B}$-cell $\mathrm{V}$ gene was shown to have a direct clinical impact in CV patients, based on its association with higher levels of rheumatoid factor activity and with lymphoproliferative disorders $[12,13]$.

Recently, it has been reported that the infection of hepatocytes in vitro by HCV results in a remarkable production of TSLP [14] through a mechanism regulated in a nuclear factor-kB-dependent fashion, and that TSLP is able to enhance the release of T-helper 17 differentiating cytokines by DCs. In view of this finding, it can be argued that upregulation of hepatocyte-derived TSLP plays a major role in the loss of $\mathrm{B}$-cell tolerance, resulting in the drastic expansion of B-cell populations and the stimulation of cryoglobulin production in chronically $\mathrm{HCV}$-infected patients. Since TSLP is required for the initial expansion of B1 and B2 bone marrow B-cell progenitors [15], it can also be postulated that an increase in systemic TSLP levels in HCV-infected patients enhances B-cell lymphopoiesis and the expansion of specific B-cell subsets, leading to override of some of the controls underlying B-cell tolerance.

Here, we asked whether an in vivo inducible upregulation of TSLP can be shown in patients with chronic $\mathrm{HCV}$ infection and $\mathrm{CV}$. A possible relationship between TSLP and HCV nucleocapsid core protein, devoid of envelope proteins, as a constitutive component of cryoglobulins and potentially able to cause cryoglobulin-mediated tissue injury [16] was also investigated. Our data indicate that high serum levels of TSLP parallel those of specific mRNA transcripts, both in the liver and to a higher extent in the skin of HCV-infected patients, suggesting that this cytokine plays an important role in the pathogenesis of $\mathrm{CV}$ related tissue damage.

\section{Materials and methods}

\section{Patients and controls}

Thirty-six naïve patients with a diagnosis of CV and the classical symptom triad of palpable purpura, arthralgia, and asthenia were enrolled in this study.
Eligibility criteria were as follows: no previous therapy with interferon, steroids, or immunosuppressive drugs; serum positivity for anti-HCV antibodies and $\mathrm{HCV}$ RNA; liver histology compatible with chronic active hepatitis; negativity for serum HBsAg and anti-HIV antibodies; alcohol intake <40 g/day; and currently not pregnant. The study was approved by the Independent Ethical Committee (Azienda Ospedaliero-Universitaria 'Policlinico Consorziale', Bari, Italy); written, informed consent was obtained from all patients, in accordance with the declaration of Helsinki.

Serum cryoglobulins were isolated and characterized as described elsewhere [17]. In addition to diagnostic liver biopsy, all $\mathrm{HCV}$-infected patients underwent two $3 \mathrm{~mm}$ punch biopsies from two cutaneous lesions. Control skin samples were derived from 24 chronically HCV-infected patients (16 males, mean age: $55.2 \pm$ 14.9 years) who tested negative for mixed cryoglobulinemia on three or more occasions and from 10 healthy subjects (six males, mean age: $48 \pm 9.4$ years), all of them undergoing surgical procedures because of inguinal or abdominal hernias, subcutaneous nodules, cutaneous squamous cell carcinoma, saphenectomy, or nodal nevi. Liver and skin biopsy specimens were either formalinfixed and paraffin-embedded for routine histological examination or embedded at the optimal cutting temperature, snap frozen, and stored at $-80^{\circ} \mathrm{C}$ until sectioning for use in immunofluorescence studies. Portions of the biopsy samples were prepared for molecular analyses. The specimens were placed in RNase-free microtubes and immediately frozen in liquid nitrogen until RNA extraction.

Patients were treated with pegylated interferon alpha/ ribavirin (pIFN $\alpha / \mathrm{RBV}$ ) combination therapy. Those infected with genotype 2 and genotype 3 were treated for 6 months, and those infected with genotype 1 for 12 months. Patients were reassessed 6 months after discontinuation of therapy to establish whether they had achieved a sustained virological response.

Virological, epidemiological, histological, and laboratory features as well as major symptomatology are summarized in Table 1.

\section{Laboratory parameters}

Serum HCV antibodies were detected by secondgeneration enzyme-linked immunosorbent assay and then confirmed by third-generation enzyme-linked immunosorbent assay (Abbott Lab, Chicago, IL, USA) in the first 18 patients enrolled in this study. The last method was consistently employed in the remaining 42 patients. Serum HCV RNA was determined by RTPCR (Roche Diagnostics, Branchburg, NJ, USA) and quantified with the Versant HCV RNA quantitative 3.0 assay (Siemens Healthcare, Erlangen, Germany). HCV 
Table 1 Virological, epidemiological, histological, laboratory, and clinical characteristics of chronically HCV-infected patients with and without cryoglobulinemic vasculitis

\begin{tabular}{|c|c|c|c|}
\hline & With CV $(n=36)$ & Without CV $(n=24)$ & $P$ value $^{\mathrm{a}}$ \\
\hline \multicolumn{4}{|l|}{ Virology } \\
\hline Serum HCV RNA & $36(100)$ & $24(100)$ & \\
\hline • Titer (log IU/ml) & $5.9(4.3$ to 6.9$)$ & $6.2(5.9$ to 6.7$)$ & NS \\
\hline Serum HCV core protein & $36(100)$ & $24(100)$ & \\
\hline • Titer (pg/ml) & 15 (0.8 to 130$)$ & $46(0.2$ to 385$)$ & 0.08 \\
\hline \multicolumn{4}{|l|}{ HCV genotype } \\
\hline - Genotype 1 & $21(58)$ & $14(58)$ & NS \\
\hline - Genotype 2 & $15(42)$ & $8(33)$ & NS \\
\hline - Genotype 3 & 0 & $2(9)$ & NS \\
\hline Anti-HCV antibodies & $36(100)$ & $24(100)$ & \\
\hline $\mathrm{HBsAg}$ & 0 & 0 & \\
\hline Anti-HIV antibodies & 0 & 0 & \\
\hline \multicolumn{4}{|l|}{ Epidemiology } \\
\hline Sex: male/female (ratio) & $9 / 27(0.33)$ & $16 / 8(2)$ & 0.003 \\
\hline Age (years) & $58.3 \pm 9.5$ & $55.2 \pm 14.9$ & NS \\
\hline Blood/blood product transfusion & $12(33)$ & $9(37.5)$ & NS \\
\hline \multicolumn{4}{|c|}{ Liver histology (METAVIR scoring system) } \\
\hline F0 & $2(5.6)$ & 0 & NS \\
\hline F1 & $6(16.7)$ & $4(16.7)$ & NS \\
\hline F2 & $11(30.5)$ & $9(37.5)$ & NS \\
\hline F3 & $8(22.2)$ & $4(16.7)$ & NS \\
\hline F4 & $9(25)$ & $7(29.1)$ & NS \\
\hline \multicolumn{4}{|l|}{ Laboratory } \\
\hline Cryocrit (\%) & $4(1$ to 34$)$ & 0 & \\
\hline \multicolumn{4}{|l|}{ Immunochemical type } \\
\hline ॥ & $33(91.7)$ & & \\
\hline III & $3(8.3)$ & & \\
\hline $\mathrm{RF}(\mathrm{IU} / \mathrm{ml}, \leq 20)$ & 101 (2 to 2,950$)$ & 12 (2 to 28$)$ & $<0.0001$ \\
\hline \multicolumn{4}{|l|}{ Immunoglobulins } \\
\hline $\operatorname{lgM}$ (mg/dl, 40 to 230$)$ & 294 (73 to 1,050$)$ & 142 (28 to 201) & $<0.0001$ \\
\hline \multicolumn{4}{|l|}{ Complement fractions } \\
\hline C1q (mg/dl, 21 to 39) & 37 (34 to 75) & 28 (23 to 46$)$ & NS \\
\hline C3 (mg/dl, 90 to 180 ) & $102(44$ to 167$)$ & 101 (85 to 109) & NS \\
\hline C4 (mg/dl, 10 to 40) & 2.5 (1 to 19$)$ & 14 (9 to 20$)$ & $<0.0001$ \\
\hline $\mathrm{ALT}(\mathrm{IU} / \mathrm{I}, \leq 30)$ & 59.5 (33 to 124$)$ & 83 (63 to 231) & NS \\
\hline \multicolumn{4}{|l|}{ Peripheral lymphocytogram } \\
\hline CD20 $(\%, 10.2 \pm 5.4)$ & 15.5 (5.5 to 81$)$ & 10.3 (7 to 25$)$ & 0.04 \\
\hline \multicolumn{4}{|l|}{ Circulating B-cell clonalities } \\
\hline Monoclonal & $21(58.4)$ & 0 & $<0.0001$ \\
\hline Oligoclonal & $12(33.3)$ & $2(8.3)$ & 0.03 \\
\hline Polyclonal & $3(8.3)$ & $22(91.7)$ & $<0.0001$ \\
\hline
\end{tabular}


Table 1 Virological, epidemiological, histological, laboratory, and clinical characteristics of chronically HCV-infected patients with and without cryoglobulinemic vasculitis (Continued)

\begin{tabular}{llc}
\hline Clinical features & & 0 \\
Palpable purpura & $27(75)$ & $4(16.7)$ \\
Weakness & $24(66.7)$ & $3(12.5)$ \\
Arthralgias/nonerosive arthritis & $27(75)$ & $1(4.2)$ \\
Cutaneous ulcers & $21(58.3)$ & 0 \\
Peripheral neuropathies & $18(50)$ & 0 \\
Renal disease & $9(25)$ &
\end{tabular}

Data presented as $n$ (\%), median (range) or mean \pm standard deviation. CV, cryoglobulinemic vasculitis; HCV, hepatitis C virus; NS, not significant; RF, rheumatoid factor. ${ }^{a} P<0.05$ was defined as significant.

genotyping was performed with INNO-LiPA (Innogenetics NV, Ghent, Belgium).

\section{Soluble thymic stromal lymphopoietin}

Immunoreactive TSLP in serum samples was quantified using an enzyme-linked immunosorbent assay with matched antibodies, according to the basic laboratory protocol provided by the manufacturer (R\&D Systems, Minneapolis, MN, USA). TSLP protein was quantified with reference to serial dilutions of the recombinant standards, falling within the linear part of the standard curve for each specific TSLP value measured. The sensitivity threshold of the TSLP assay is $6.7 \mathrm{pg} / \mathrm{ml}$. Each data point represents readings from two independent assays performed in duplicate.

\section{Circulating hepatitis $\mathrm{C}$ virus core protein}

Serum nonenveloped $\mathrm{HCV}$ core protein was tested using Architect HCV Ag (Abbott Diagnostics, Wiesbaden, Germany), a fully automated, quantitative, chemiluminescent microparticle immunoassay for the detection of nonenveloped $\mathrm{HCV}$ core protein in $\mathrm{HCV}$-infected sera [16].

\section{Tissue RNA isolation and PCR amplification}

Total RNA was extracted from liver and skin samples with the RNeasy Mini kit (Qiagen, Hilden, Germany), according to the manufacturer's protocol, and reverse transcribed to cDNA using the iScript Select cDNA synthesis kit (Bio-Rad Laboratories, Hercules, CA, USA). Five microliters of CDNA were used in a nested PCR for HCV RNA detection together with the AmpliTaq Gold PCR master mix (Applied Biosystems, Foster City, CA, USA) and the following primer sets targeting the $5^{\prime}$-untranslated region: sense 5'GGGGGCGACACTCCACCA-3' (position 15 to 32) and anti-sense 5' ${ }^{\prime}$-TCGCGACCCAACACTACTC-3' (position 256 to 274) for the first round of amplification; and the inner primers sense 5'-GAGTGTCGTG CAGCCTCCAG-3' (position 98 to 117) and anti- sense 5'-CTCGGCTAGCAGTCTCGCGG-3' (position 239 to 258) for the second round.

An additional PCR for TSLP mRNA was carried out using $5 \mu \mathrm{l}$ cDNA, the AmpliTaq Gold PCR master mix (Applied Biosystems), and the QuantiTect human TSLP primer assay (Qiagen). This primer set targets exons $1 / 2 / 3$ and amplifies a region of 94 base pairs in the two transcripts $(2,629$ base pairs and 3,834 base pairs, respectively).

\section{Real-time RT-PCR for TSLP mRNA quantification}

TSLP mRNA was measured in patient samples by absolute real-time RT-PCR quantification. The reaction was performed using the QuantiTect human TSLP primer assay (Qiagen) and FastStart DNA Master SYBR Green I (Roche Diagnostics, Mannheim, Germany) on a LightCycler 1.5 instrument (Roche Diagnostics), according to the manufacturer's protocol. The cycling conditions were $95^{\circ} \mathrm{C}$ for 15 minutes, 45 cycles of $94^{\circ} \mathrm{C}$ for 15 seconds, $55^{\circ} \mathrm{C}$ for 20 seconds, and $72^{\circ} \mathrm{C}$ for 20 seconds. The final concentration of TSLP mRNA was expressed as copies of mRNA per nanogram of total RNA.

Real-time RT-PCR for HCV RNA quantitation was performed using the RNA Master HybProbe kit (Roche Diagnostics) and the following primers and probes: 5 ' $-\mathrm{A}$ GCGTCTAGCCATGGCGT (sense), 5'-CAAGCACCCT ATCAGGCAGT (antisense), 5'-LC640-CCCGGGAGAG CCATAGTGGTCTG-PH $\left(5^{\prime}\right.$ LCRed640) and 5'-GCA GCCTCCAGGACCCCCC-FL (3'HCV-G-Fitch) (TIB MOLBIOL, Berlin, Germany). To generate a standard curve, serial dilutions of the AcroMetrix HCV Mid Control (AcroMetrix, Benicia, CA, USA) were prepared. The HCV RNA concentration was calculated as International Units per nanogram of total RNA; the sensitivity was 20 IU. Each sample and standard curve point was run in duplicate.

\section{Construction of standards for real-time RT-PCR absolute quantification}

The TSLP standard was constructed by cloning product of real-time RT-PCR obtained using a bioinformatically 
verified primer assay (QuantiTect Primer Assay; Qiagen). The PCR product was visualized on a $2 \%$ agarose gel and the respective band was excised and loaded onto a DNA purification column (DNA gel extraction kit; Millipore, Billerica, MA, USA). The purified PCR product was cloned into a pGEM-T Easy vector using pGEM-T Easy vector system II (Promega, Madison, WI, USA), according to the manufacturer's protocol. The recombinant vector was transformed into JM109 Escherichia coli competent cells (Promega). The transformants were plated onto duplicate LB/ampicillin/ IPTG/X-Gal plates, incubated overnight at $37^{\circ} \mathrm{C}$, and then selected and processed for plasmid isolation. Five milliliters of Luria-Bertani broth cultures of single colonies were grown overnight at $37^{\circ} \mathrm{C}$ with shaking at $200 \mathrm{rpm}$. The DNA plasmid was purified using the QIAprep spin miniprep kit (Qiagen) and then solubilized in $100 \mu \mathrm{l}$ of $10 \mathrm{mM}$ Tris- $\mathrm{HCl}$ ( $\mathrm{pH} 8.5$ ) buffer. To confirm the sequence of the cloned product, DNA sequencing was performed using the BigDye Terminator v1.1 cycle sequencing kit and ABI Prism 310 genetic analyzer (both Applied Biosystems). The purified plasmid was quantified and the copy number calculated as follows:

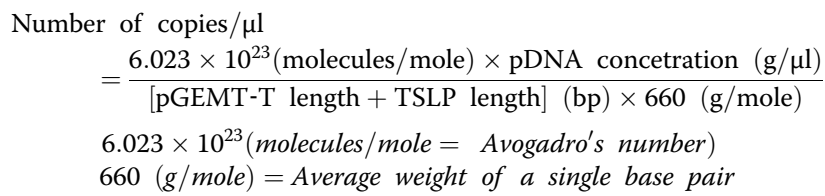

where $6,023 \times 10^{23}$ (molecules/mole) is Avogadro's number and $660(\mathrm{~g} / \mathrm{mole})$ is the average weight of a single base pair. The standard curve was prepared from five-point serial 10-fold dilutions, starting from 300,000 copies.

\section{Thymic stromal lymphopoietin protein detection}

TSLP protein in liver and skin biopsy samples was detected by indirect immunofluorescence, using a goat anti-human TSLP antibody (Biorbyrt, Cambridge, UK) at a working concentration of $10 \mu \mathrm{g} / \mathrm{ml}$. As a positive control, human tonsil sections were employed. The samples were incubated with the primary antibody for 3 hours at room temperature. Isotype-matched antibodies were used for control staining and a fluorescein isothiocyanate-conjugated rabbit anti-goat antibody $\mathrm{F}(\mathrm{ab})_{2}$ fragment (Dako Denmark, Glostrup, Denmark) as the secondary reagent. The latter was incubated with the samples for 2 hours at room temperature. To block a positive reaction on selected samples, the primary antibody was preincubated with human recombinant TSLP protein $(5 \mathrm{ng} / \mathrm{ml})$.

\section{Hepatitis $\mathrm{C}$ virus core protein detection}

A two-stage indirect immunofluorescence procedure was carried out as described previously [18], using an antibody (clone 4,6 E7-F6) that recognizes amino acids 29 to 43 (working concentration $0.9 \mathrm{pg} / \mathrm{ml}$ ).

\section{B-cell clonal expansions}

The immunoglobulin heavy chain variable-diversityjoining gene segments were amplified in duplicate reactions according to the Fr3 protocol, as described elsewhere $[9,10]$. Consensus primers for the $\mathrm{V}$ and $J$ regions were: an upstream primer complementary to the third framework V region, 5 '-ACACGGC(C/T)(C/G)TGTATTACTGT-3'; and a downstream primer directed to a conserved sequence of the J region, 5'-TGAGGAGACGGTGACC-3', and in the second-round amplification of an inner conserved sequence of the same $J$ region, 5'-GTGACCAGGGTNCCTTGGCCCCAG-3'.

\section{Statistical analysis}

Descriptive statistics included the mean or median as appropriate for continuous variables, and the frequency (\%) for categorical variables. In the univariate analysis, chi-square and Fisher's exact tests were used as appropriate to compare categorical variables, and the nonparametric Mann-Whitney test to compare continuous variables. The differences were considered significant at $P<0.05$. A Spearman rank correlation coefficient $(r)$ test was used to evaluate the relationships between variables. All statistical analyses were performed using IBM SPSS statistics version 19.0 (Armonk, NY, USA).

\section{Results}

\section{Study population}

As shown in Table 1, all CV patients were anti-HCVpositive, viremic, and had circulating nonenveloped HCV core protein. Except for a moderate prevalence of genotype 1, no distinct distribution profile emerged among the patients. Liver damage was histologically defined. Laboratory parameters indicated normal serum levels of complement components $\mathrm{C} 1 \mathrm{q}$ and $\mathrm{C} 3$, but remarkably low serum levels of C4. Molecular analyses aimed at determining immunoglobulin heavy chain variable-diversity-joining gene rearrangements showed that B-cell clonalities were expanded in $33(92 \%) \mathrm{CV}$ patients and in only two $(8 \%)$ non-CV patients $(P<0.0001)$. The mean percentage of $\mathrm{CD} 20^{+} \mathrm{B}$ cells was higher in $\mathrm{CV}$ than in non-CV patients $(P=0.04)$.

There was a strikingly higher number of female patients with mixed cryoglobulinemia (27 out of $36,75 \%$ ). This reflects the higher female prevalence in all major cohorts of CV - including our own series of 141 patients, $68 \%$ of whom were females [19]. However, serum TSLP levels were not significantly different between sexes in each group of patients. 
Among the clinical symptoms of $\mathrm{CV}$ patients, palpable purpura, asthenia, and arthralgia/arthritis were recorded with high frequency. Peri-malleolar and/or pre-tibial cutaneous ulcers were also found in over one-half of the patients. Long-lasting hyperpigmentation affecting the legs to a variable extent, as the result of recurrent purpuric eruptions, was also almost invariably present. Skin histology showed leukocytoclastic vasculitis in 32 patients $(89 \%)$, whereas pandermal vasculitis characterized by vessel thrombosis and severe endothelial alterations was diagnosed in the remaining four patients (11\%). Sensory-motor peripheral neuropathy was demonstrated in one-half of the patients, in whom electromyography prevalently revealed symmetrical, distal polyneuropathy and, less frequently, mononeuritis multiplex. Renal damage was diagnosed in $25 \%$ of the patients, with renal biopsy showing membrano-proliferative glomerulonephritis in $78 \%$ and membranous nephropathy with segmental glomerulosclerosis in the remaining $22 \%$.

\section{In situ TSLP and HCV core protein immune detection}

TSLP-specific immune reactive material was demonstrated in 31 of $36(86 \%)$ and 19 of 24 (79\%) liver tissue specimens from $\mathrm{CV}$ and non- $\mathrm{CV}$ patients, respectively. As shown in Figure 1, although TSLP was detected in the cytoplasm of hepatocytes, the number of stainable liver cells varied greatly among liver specimens: TSLP was in fact randomly distributed throughout the liver sections but without an obvious topographical relationship to liver structures. No distinct nuclear staining pattern was noted. Positivity of cell membranes or submembranes was infrequent (Figure 1A,B). In addition, TSLP immune deposits were detected in portal tracts containing inflammatory infiltrates (Figure 1C) and in biliary epithelium (Figure 1D,E).

TSLP and HCV core proteins were studied in skin biopsy samples from all $\mathrm{CV}$ and non-CV patients and from healthy controls. The results showed that TSLP protein was mostly restricted to the basal and suprabasal layers of the epidermis (Figure 2A,B,C) in the large majority of both CV patients $(27 / 31,87 \%)$ and non-CV patients $(15 / 19,79 \%)$. No peculiar features were detected in the remaining TSLP distribution patterns. Analysis of the dermal layer showed TSLP protein deposition mainly in blood vessel walls (Figure 2D). Similarly, HCV core protein could be demonstrated within and/or around dermal vessels. Intravascular core reactivity appeared as coarse deposits completely filling the vessel lumen or as immune reactants within vessel walls and in the perivascular area (Figure 2G,H,I,J). Attempts to detect deposits of HCV-encoded core protein in keratinocytes consistently met with failure. None of the skin biopsy tissues from non-CV patients or healthy individuals were positive for TSLP or HCV core protein.

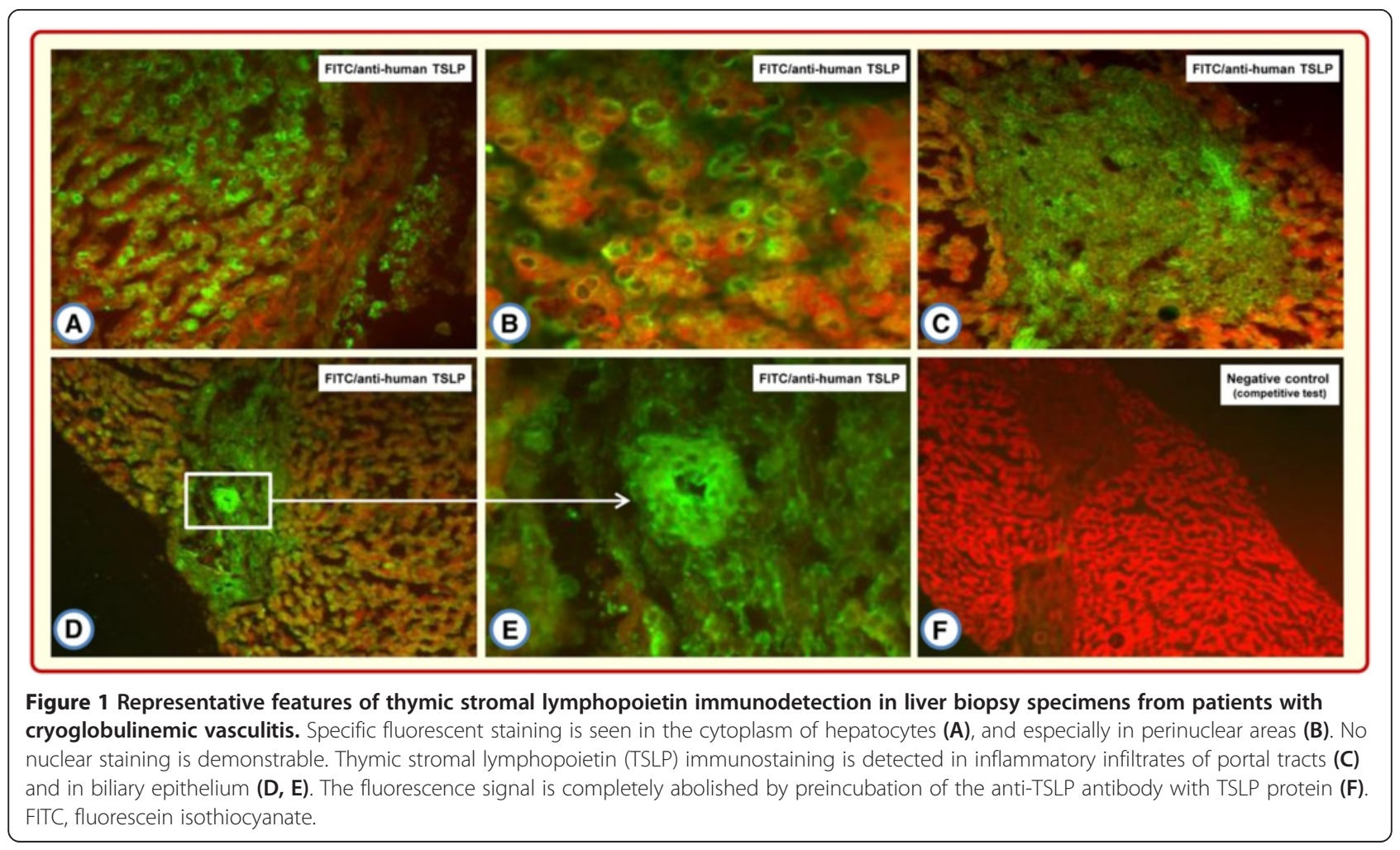




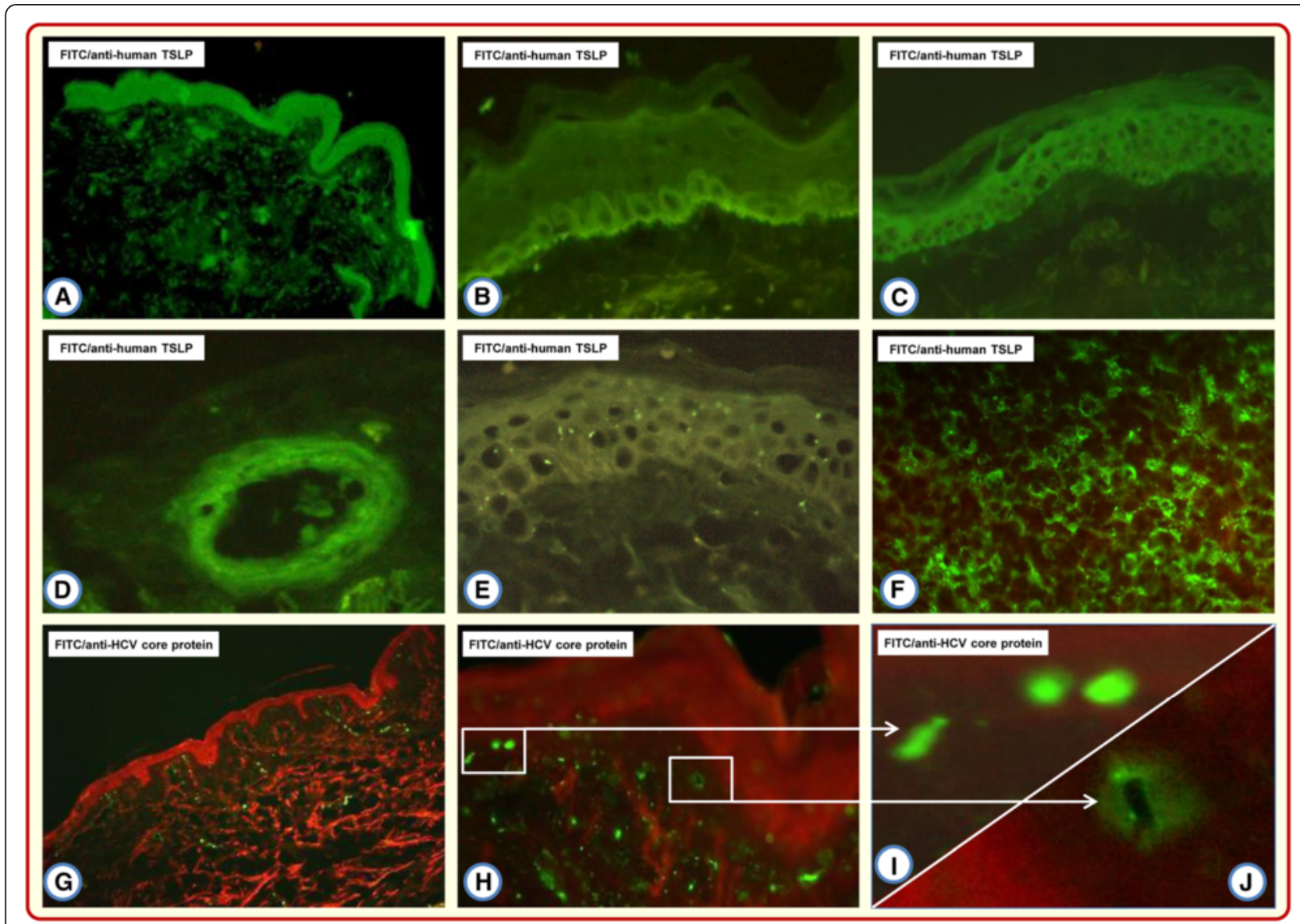

Figure 2 Detection of thymic stromal lymphopoietin and hepatitis $\mathrm{C}$ virus core proteins in the skin biopsies of cryoglobulinemic vasculitis patients by indirect immunofluorescence. Thymic stromal lymphopoietin (TSLP) immunoreactivity is present in the epidermis (A), both in basal (B) and suprabasal (C) layers. In the dermis, TSLP immune reactants are localized in the vessel walls (D). There is no TSLP signal in the skin of normal subjects (E). Intense signal of TSLP-specific immune reactants in human tonsil section as positive control (F). Hepatitis $C$ virus ( $\mathrm{HCV}$ ) core protein immune deposits are found only in the dermis, whereas keratinocytes never displayed positivity (G). Intravascular HCV core immunostaining completely fills the vessel lumen $\mathbf{( H , ~ I ) ~ o r ~ i s ~ l o c a l i z e d ~ p e r i v a s c u l a r l y ~ ( J ) . ~ F I T C , ~ f l u o r e s c e i n ~ i s o t h i o c y a n a t e . ~}$

Thymic stromal lymphopoietin mRNA and HCV RNA amplicons in the skin

Notably, although TSLP mRNA expression was demonstrated in the skin samples of $\mathrm{CV}$ and non-CV patients and in those of healthy controls, HCV RNA amplification products were present in only two (6\%) of 36 skin specimens from $\mathrm{CV}$ patients and in none of those from either the non-CV patients or healthy individuals.

The relationship between TSLP protein, specific mRNA expression, and the occurrence of $\mathrm{HCV}$ core protein or viral RNA is summarized in Table 2. TSLP protein was upregulated and revealed by immunofluorescence in $33(92 \%)$

Table 2 Thymic stromal lymphopoietin protein and gene expression in relation to HCV core protein and HCV RNA detection in skin tissue from chronically HCV-infected patients with and without cryoglobulinemic vasculitis and from healthy controls

\begin{tabular}{|c|c|c|c|c|c|}
\hline \multirow{3}{*}{ Category } & \multicolumn{5}{|c|}{ Skin tissue } \\
\hline & \multicolumn{3}{|c|}{ TSLP } & \multicolumn{2}{|c|}{$\mathrm{HCV}$} \\
\hline & Protein & mRNA & $(\%)$ & Core protein & RNA \\
\hline \multirow[t]{2}{*}{ Cryoglobulinemic patients $(n=36)$} & $33(92)$ & $36(100)$ & & $29(81)$ & $2(6)$ \\
\hline & $P<0.0001$ & & & $P<0.0001$ & \\
\hline \multirow[t]{2}{*}{ Noncryoglobulinemic patients $(n=24)$} & $5(21)$ & $24(100)$ & & $2(8)$ & 0 \\
\hline & NS & & & NS & \\
\hline Healthy controls $(n=10)$ & 0 & $10(100)$ & & 0 & 0 \\
\hline
\end{tabular}

$\mathrm{HCV}$, hepatitis C virus; NS, not significant; TSLP, thymic stromal lymphopoietin. 
$\mathrm{CV}$ patients and in five $(21 \%)$ non- $\mathrm{CV}$ patients $(P<0.0001)$, but in none of the controls $(P<0.0001)$. HCV core protein was detected in the skin tissue of 29 (81\%) CV patients and two $(8 \%)$ non-CV patients $(P<0.0001)$. Conversely, all of the skin biopsies from healthy subjects tested negative for the immune detection of both TSLP protein and HCV core protein.

\section{Thymic stromal lymphopoietin gene quantitation in liver and skin compartments}

Potential differences in TSLP gene regulation between specific biologic compartments were searched for by measuring mRNA expression levels in the skin and in the corresponding liver tissue samples of $\mathrm{CV}$ and non$\mathrm{CV}$ patients (Figure 3). A median of 434 (range, 10 to 1,026) mRNA copies/ng total RNA was estimated in the skin and 3.4 (range, 2.1 to 74 ) mRNA copies/ng total RNA in the liver samples $(P<0.0001)$ of CV patients. In sharp contrast, TSLP gene expression was significantly downregulated in the skin compared with the liver in non-CV patients, with a median of 0.29 (range, 0.13 to 22.2) mRNA copies/ng total RNA and 3.3 (range, 0.75 to 28.4) mRNA copies/ng total RNA $(P<0.0001)$, respectively. TSLP gene expression was thus strikingly different in the skin from $\mathrm{CV}$ patients compared with that from non-CV patients $(P<0.0001)$.

\section{Serum TSLP soluble protein}

Basal serum levels of TSLP protein were measured in all $\mathrm{HCV}$-positive $\mathrm{CV}$ and non-CV patients and in all healthy subjects. At the time of serum TSLP measurement, none of the HCV-infected patients was receiving specific antiviral treatment and/or immunosuppressive drugs. TSLP levels were significantly higher in CV patients (median, $186 \mathrm{pg} /$ $\mathrm{ml}$; range, 97 to 435 ) than in either non-CV patients (median, $70.7 \mathrm{pg} / \mathrm{ml}$; range, 16 to 157 ) or healthy subjects (median, $0 \mathrm{pg} / \mathrm{ml}$; range, 0 to 18$)(P<0.0001$ in both cases $)$.

Spearman's rank correlation test was used to assess the strength of the association between basal TSLP concentrations and virologic and laboratory parameters (Table 3). A positive correlation was found with serum $\mathrm{HCV}$ nonenveloped core protein $(P=0.02), \mathrm{C} 1 \mathrm{q}(P=0.003), \mathrm{C} 3 \quad(P=$ $0.0001)$, and number of peripheral $\mathrm{CD} 20^{+}$cells $(P=0.0009)$. On the contrary, there was no relationship with mean age of the patients, circulating HCV RNA or cryoprotein levels, rheumatoid factor, serum concentrations of IgM and $\mathrm{C} 4$ complement component, and alanine aminotransferase activity.

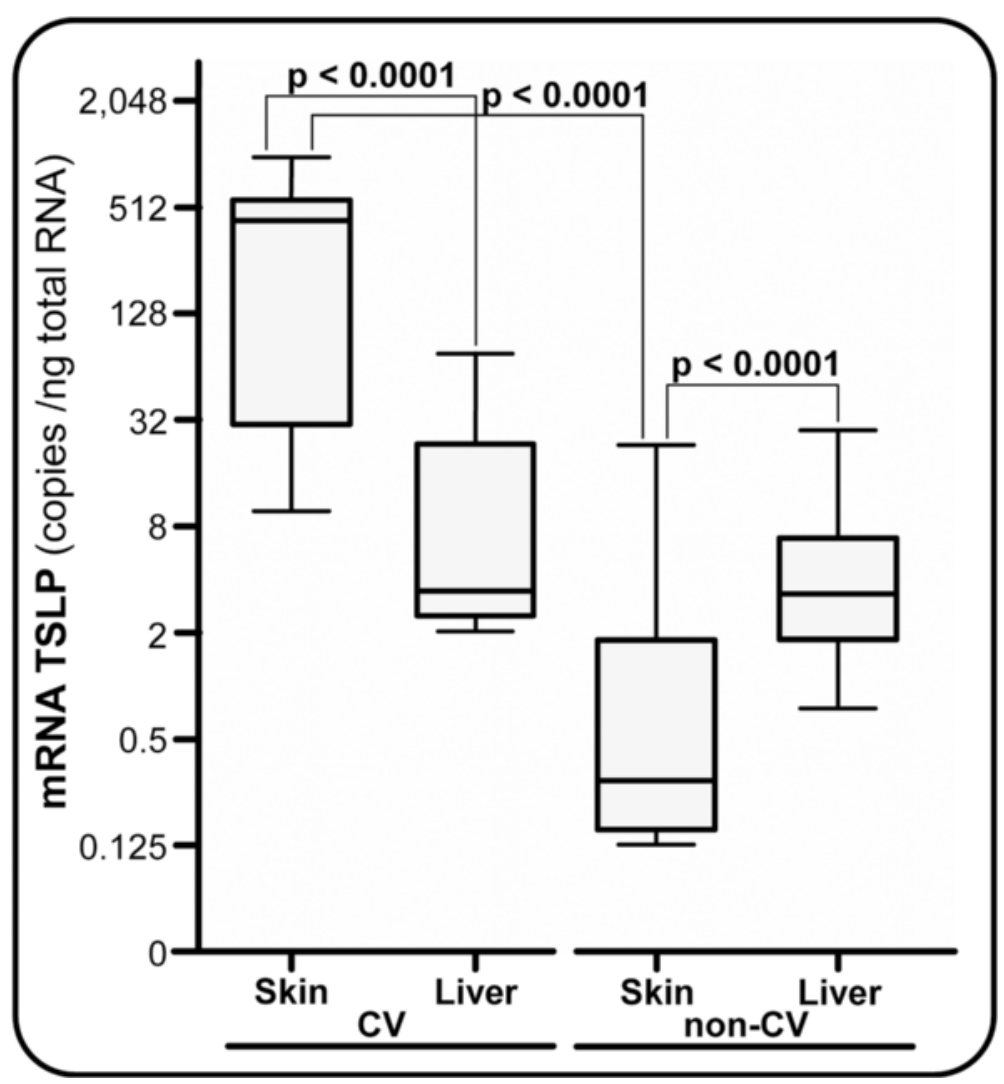

Figure 3 Thymic stromal lymphopoietin gene expression measurement. Absolute quantitative real-time RT-PCR in the skin and liver tissues of cryoglobulinemic vasculitis (CV) and non-CV patients. TSLP, thymic stromal lymphopoietin. 
Table 3 Spearman's rank correlation analysis of serum thymic stromal lymphopoietin levels versus laboratory/clinical parameters in 36 patients with HCV-related cryoglobulinemic vasculitis

\begin{tabular}{|c|c|c|c|}
\hline Parameter & $r$ coefficient & $95 \%$ confidence interval & $P$ value $^{\mathrm{a}}$ \\
\hline \multicolumn{4}{|l|}{ Epidemiology } \\
\hline Age (years) & -0.2144 & -0.5147 to 0.1328 & 0.2092 \\
\hline \multicolumn{4}{|l|}{ Virology } \\
\hline Serum HCV RNA (log IU/ml) & -0.2000 & -0.5307 to 0.1836 & 0.2893 \\
\hline Serum HCV nonenveloped core protein $(\mathrm{pg} / \mathrm{ml})$ & 0.4182 & 0.0768 to 0.6718 & 0.02 \\
\hline \multicolumn{4}{|l|}{ Laboratory } \\
\hline Cryocrit (\%) & -0.0845 & -0.4104 to 0.2605 & 0.6241 \\
\hline Rheumatoid factor (IU/ml) & -0.1182 & -0.4520 to 0.2447 & 0.5125 \\
\hline $\lg M(\mathrm{mg} / \mathrm{dl})$ & 0.1000 & -0.2619 to 0.4373 & 0.5798 \\
\hline $\mathrm{Clq}(\mathrm{mg} / \mathrm{dl})$ & 0.6571 & 0.2605 to 0.8640 & 0.0030 \\
\hline C3 (mg/dl) & 0.7335 & 0.5137 to 0.8629 & 0.0001 \\
\hline $\mathrm{C} 4(\mathrm{mg} / \mathrm{dl})$ & 0.1388 & -0.2085 to 0.4551 & 0.4194 \\
\hline ALT (IU/I) & 0.1763 & -0.2072 to 0.5129 & 0.3514 \\
\hline Peripheral CD20+ cells (\%) & 0.7143 & 0.3581 to 0.8890 & 0.0009 \\
\hline
\end{tabular}

HCV, hepatitis $C$ virus. ${ }^{a} P<0.05$ was defined as significant.

\section{Therapy-induced modifications of serum TSLP levels}

Changes in the serum TSLP levels were investigated following therapy in all CV patients. Baseline serum levels of this cytokine were slightly but not significantly lower in 16 responder patients $(44.4 \%)$ compared with 20 nonresponder patients (55.6\%). In the first group, the administration of $\mathrm{pIFN} \alpha / \mathrm{RBV}$ combination therapy resulted in a dramatic improvement of cryoglobulinrelated signs and symptoms, a remarkable decrement of the cryocrit, and the disappearance of serum HCV RNA. This complete response was found to be associated with a significant drop in TSLP serum levels (Figure 4). In sharp contrast, TSLP levels remained roughly unchanged in the group of unresponsive patients.

\section{Discussion}

The main features of this study can be summarized as follows: untreated patients with HCV-related CV exhibit a significant median increase in the TSLP mRNA transcripts of skin mRNA tissue samples compared with the corresponding liver samples; basal and suprabasal keratinocytes and hepatocytes have been identified as the sources of TSLP; serum TSLP protein levels are significantly higher in CV patients than in either non-CV patients or healthy subjects; higher serum levels of TSLP in CV patients are associated with a higher frequency of circulating monoclonal/oligoclonal expansions of B cells in the large majority of these patients; and achievement of complete response by the combined pIFN $\alpha / \mathrm{RBV}$ therapy results in a highly significant reduction of serum TSLP.

One obvious question stemming from our study is whether the correlations reported above indeed reflect a specific mechanistic role of TSLP in the onset of CV or are simply the result of generalized immune activation in this condition. Several observations, however, argue against a simplistic interpretation. We have already mentioned in the Introduction that TSLP transgenic mice often develop mixed cryoglobulins and cryoglobulinemic type I membrano-proliferative glomerulonephritis as well as additional features that closely resemble important aspects of the human disease [7]. In addition, a growing number of studies, highlighted in two recent reviews [20,21], have provided insightful advances into TSLP's pleomorphic roles in diverse disease conditions, including allergy, autoimmunity, and cancer, thus making it unlikely that the elevated TSLP levels are the consequence of rather than the driver of CV.

The changes within the skin microenvironment that induce TSLP gene expression and the upregulation of TSLP protein are as yet unclear, given that in the keratinocytes of $\mathrm{HCV}$-infected non-CV patients TSLP gene expression was downregulated and TSLP protein production was absent. It seems unlikely that the upregulation of TSLP in the skin of CV patients is directly dependent on $\mathrm{HCV}$, in that we have never been able to convincingly demonstrate HCV RNA amplicons in skin tissue samples and have no evidence of a direct relationship between HCV RNA levels and the type of and/or the extent of skin damage.

By analogy with the results obtained in vitro by Lee and colleagues [14], we have shown in vivo that chronic $\mathrm{HCV}$ infection is able to induce TSLP gene expression and the hepatocyte production of the protein, which is then released in the circulation. In addition, circulating cold-precipitable immune complexes are crucial to the pathogenesis of cryoglobulin-related cutaneous vasculitis 


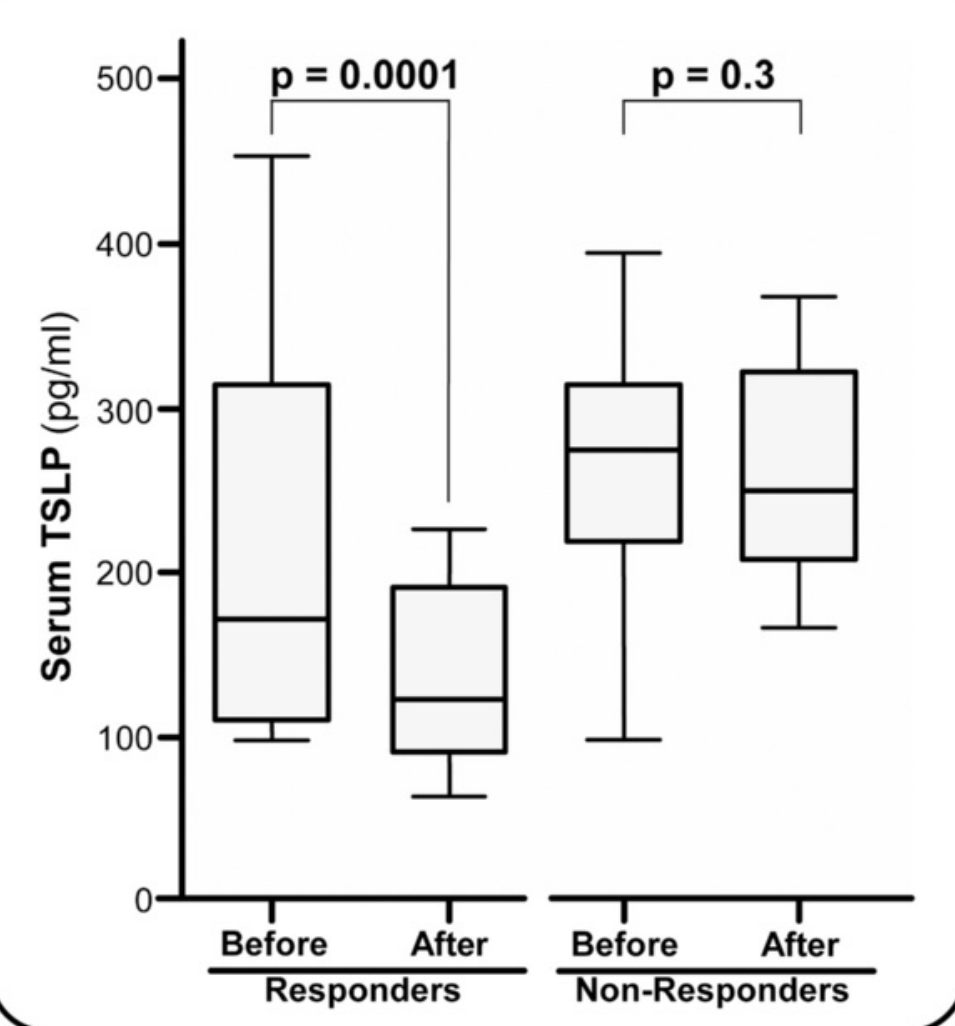

Figure 4 Serum levels of soluble thymic stromal lymphopoietin protein in cryoglobulinemic vasculitis patients responsive and unresponsive to antiviral therapy. TSLP, thymic stromal lymphopoietin.

[11], characterized by activation of the complement pathway, with subsequent damage to endothelial cells and the initiation of a local inflammatory response [12,22].

TSLP protein was highly expressed in skin biopsies from CV patients, forming large deposits in dermal vessel walls, a finding reminiscent of the TSLP deposits in the skin of patients with diffuse cutaneous systemic sclerosis [23]. It can be assumed that HCV core protein affects the pathobiology of $\mathrm{T}$-cell responses by inducing anergy-related genes [24] and in loco generation of a Thelper 17 response [25]. This raises the intriguing possibility of a cross-talk between hepatocyte-derived TSLP and skin tissue damage, resulting in the polarization of DCs and $\mathrm{CD}_{4}^{+} \mathrm{T}$-cell differentiation [1].

In response to pathogens, DCs both produce and respond to TSLP, thereby creating a potential autocrine loop [26]. According to this view, DCs can be instructed by TSLP produced in inflamed tissues to migrate into the interstitial environment of peripheral tissues and to initiate a suitable immune response [27]. Notably, because of the critical role of nuclear factor- $\mathrm{k} B$ downstream of the toll-like receptor signaling pathway, it is not surprising that toll-like receptor agonists as well as infectious agents are effective inducers of TSLP expression in epithelial cells [28].

Although TSLP expression can be induced by the ongoing $\mathrm{HCV}$ infection of hepatocytes, we failed to demonstrate a direct relationship between systemic levels of TSLP and circulating viral RNA. Conversely, serum TSLP levels correlated well with those of HCV core protein, indicating an association between higher amounts of the former and HCV RNA-free structures.

An important point of our study is the detection of a significant reduction of TSLP serum levels in patients responsive to $\mathrm{pIFN} \alpha / \mathrm{RBV}$ combination therapy, probably reflecting the appropriate blockade of TSLP release by hepatocytes and keratinocytes. Conversely, the unchanged levels in unresponsive patients suggest persisting HCV-mediated induction of TSLP production that contributes to immune system activation. Although the addition of the anti-CD20 monoclonal antibody rituximab to the pIFN $\alpha / R B V$ combination has been shown to result in higher long-term response rates [29], rituximab alone does not seem to affect the serum TSLP levels: in a pilot study carried out in nine $\mathrm{CV}$ patients different from those enrolled in this study, no significant variations of 
serum TSLP levels were detected following the administration of four weekly intravenous infusions of $375 \mathrm{mg} / \mathrm{m}^{2}$ rituximab monotherapy (data not shown).

In a proof-of-concept study, the administration of a fully human anti-TSLP monoclonal antibody G2 $\lambda$ to a small cohort of patients with stable allergic asthma resulted in a significant attenuation of allergy-induced early and late asthmatic responses [30]. No therapeutic proof-of-principle attempts with anti-TSLP monoclonal antibodies have so far been reported in CV patients, but it seems reasonable to hypothesize that TSLP blockade is a potential, targeted therapeutic strategy that could be added to the current therapies of $\mathrm{CV}$ [31].

\section{Conclusions}

This study points out a novel biological role for TSLP. Cutaneous expression of TSLP by the keratinocytes of patients with HCV-related CV may be pivotal in perpetuating the activation of tissue-resident immunocytes and in attracting inflammatory cells, thus creating an environment favorable to the onset of vasculitis. The local production of TSLP by hepatocytes as well as keratinocytes causes a significant increase in its systemic concentrations, a step sufficient to promote a break in B-cell homeostasis and likely to induce B-lineage-dependent autoimmunity.

Further studies are necessary to evaluate the molecular basis underlying TSLP upregulation and B-cell derangement in patients with $\mathrm{HCV}$-related CV. Although a deeper comprehension of cell-specific signaling pathways awaits to be defined, given that TSLP has been found capable of directly acting on $\mathrm{CD} 4^{+} \mathrm{T}$ cells and of promoting proliferation and T-helper 2 differentiation of naïve $\mathrm{CD} 4^{+} \mathrm{T}$ cells through the induction of interleukin4 [20], it seems reasonable to hypothesize that the overexpression of mRNA TSLP in the skin of CV patients and the consequent cytokine milieu play an important role in the inflammatory responses that characterize this peculiar type of $\mathrm{HCV}$-induced vasculitis.

\section{Abbreviations}

CV: cryoglobulinemic vasculitis; DC: dendritic cell; HCV: hepatitis C virus; IFNa: interferon alpha; RBV: ribavirin; TSLP: thymic stromal lymphopoietin.

\section{Competing interests}

The authors declare that they have no competing interests.

\section{Authors' contributions}

All authors were involved in drafting the article or revising it critically for important intellectual content. DS and FD had full access to all of the data in the study, take responsibility for the integrity of the data and the accuracy of the data analysis, and were responsible for study conception and design. SR, SS, and FP were responsible for acquisition of data. DS, SR, and FD were responsible for analysis and interpretation of data. All authors read and approved the final manuscript.

\section{Acknowledgements}

This work was supported by the Italian Foundation for Cancer Research (grant number FIRC2013-15166), Milan, by the Cassa di Risparmio di Puglia Foundation, Bari, and by the University of Bari.

\section{Author details}

${ }^{1}$ Liver Unit, Department of Biomedical Sciences and Human Oncology, University of Bari Medical School, 11 Piazza G. Cesare, 70124 Bari, Italy.

${ }^{2}$ Institute of Internal Medicine, Department of Medical and Surgical Sciences, University of Foggia Medical School, 1 viale L. Pinto, 71122 Foggia, Italy.

Received: 16 December 2014 Accepted: 23 February 2015

Published online: 15 March 2015

\section{References}

1. Ziegler SF, Liu YJ. Thymic stromal lymphopoietin in normal and pathogenic T cell development and function. Nat Immunol. 2006;7:709-14.

2. Tanaka J, Watanabe N, Kido M, Saga K, Akamatsu T, Nishio A, et al. Human TSLP and TLR3 ligands promote differentiation of Th17 cells with a central memory phenotype under Th2-polarizing conditions. Clin Exp Allergy. 2009;39:89-100.

3. Park LS, Martin U, Garka K, Gliniak B, Di Santo JP, Muller W, et al. Cloning of the murine thymic stromal lymphopoietin (TSLP) receptor: formation of a functional heteromeric complex requires interleukin 7 receptor. J Exp Med. 2000;192:659-70.

4. Demehri S, Liu Z, Lee J, Lin MH, Crosby SD, Roberts CJ, et al. Notch-deficient skin induces a lethal systemic B-lymphoproliferative disorder by secreting TSLP, a sentinel for epidermal integrity. PLoS Biol. 2008;6:e123.

5. Yoo J, Omori M, Gyarmati D, Zhou B, Aye T, Brewer A, et al. Spontaneous atopic dermatitis in mice expressing an inducible thymic stromal lymphopoietin transgene specifically in the skin. J Exp Med. 2005;202:541-9.

6. Astrakhan A, Omori M, Nguyen T, Becker-Herman S, Iseki M, Aye T, et al. Local increase in thymic stromal lymphopoietin induces systemic alterations in B cell development. Nat Immunol. 2007;8:522-31.

7. Taneda S, Segerer S, Hudkins KL, Cui Y, Wen M, Segerer M, et al. Cryoglobulinemic glomerulonephritis in thymic stromal lymphopoietin transgenic mice. Am J Pathol. 2001;159:2355-69.

8. Saadoun D, Landau DA, Calabrese LH, Cacoub P. Hepatitis C-associated mixed cryoglobulinaemia: a crossroad between autoimmunity and lymphoproliferation. Rheumatology. 2007;46:1234-42.

9. Sansonno D, De Vita S, lacobelli AR, Cornacchiulo V, Boiocchi M, Dammacco F. Clonal analysis of intrahepatic B cells from HCV-infected patients with and without mixed cryoglobulinemia. J Immunol. 1998;160:3594-601.

10. Racanelli V, Sansonno D, Piccoli C, D'Amore FP, Tucci FA, Dammacco F. Molecular characterization of $B$ cell clonal expansions in the liver of chronically hepatitis C virus-infected patients. J Immunol. 2001;167:21-9.

11. De Re V, De Vita S, Sansonno D, Gasparotto D, Simula MP, Tucci FA, et al. Type II mixed cryoglobulinaemia as an oligo rather than a mono B-cell disorder: evidence from GeneScan and MALDI-TOF analyses. Rheumatology. 2006;45:685-93.

12. Sansonno D, Lauletta G, De Re V, Tucci FA, Gatti P, Racanelli V, et al. Intrahepatic B cell clonal expansions and extrahepatic manifestations of chronic HCV infection. Eur J Immunol. 2004;34:126-36.

13. Sansonno D, Dammacco F. Hepatitis C virus, cryoglobulinaemia, and vasculitis: immune complex relations. Lancet Infect Dis. 2005;5:227-36.

14. Lee HC, Sung SS, Krueger PD, Jo YA, Rosen HR, Ziegler SF, et al. Hepatitis C virus promotes T-helper (Th)17 responses through thymic stromal lymphopoietin production by infected hepatocytes. Hepatology. 2013;57:1314-24.

15. Ziegler SF. Thymic stromal lymphopoietin and allergic disease. J Allergy Clin Immunol. 2012;130:845-52.

16. Russi S, Sansonno D, Mariggiò MA, Vinella A, Pavone F, Lauletta G, et al. Assessment of total Hepatitis C virus (HCV) core protein in HCV-related mixed cryoglobulinemia. Arthritis Res Ther. 2014;16:R73.

17. Dammacco F, Sansonno D, Piccoli C, Tucci FA, Racanelli V. The cryoglobulins: an overview. Eur J Clin Invest. 2001;31:628-38.

18. Sansonno D, Cornacchiulo V, lacobelli AR, Di Stefano R, Lospalluti M, Dammacco F. Localization of hepatitis C virus antigens in liver and skin tissues of chronic hepatitis C virus-infected patients with mixed cryoglobulinemia. Hepatology. 1995:21:305-12.

19. Lauletta G, Russi S, Conteduca V, Sansonno L, Dammacco F, Sansonno D. Impact of cryoglobulinemic syndrome on the outcome of chronic hepatitis 
C virus infection: a 15-year prospective study. Medicine (Baltimore). 2013:92:245-56.

20. Ziegler SF, Roan F, Bell BD, Stoklasek TA, Kitajima M, Han H. The biology of thymic stromal lymphopoietin (TSLP). Adv Pharmacol. 2013;66:129-55.

21. Lo Kuan E, Ziegler SF. Thymic stromal lymphopoietin and cancer. J Immunol. 2014;193:4283-8.

22. Guo WX, Ghebrehiwet B, Weksler B, Schweitzer K, Peerschke El. Up-regulation of endothelial cell binding proteins/receptors for complement component C1q by inflammatory cytokines. J Lab Clin Med. 1999;133:541-50.

23. Christmann RB, Mathes A, Affandi AJ, Padilla C, Nazari B, Bujor AM, et al. Thymic stromal lymphopoietin is up-regulated in the skin of patients with systemic sclerosis and induces profibrotic genes and intracellular signaling that overlap with those induced by interleukin-13 and transforming growth factor $\beta$. Arthritis Rheum. 2013;65:1335-46

24. Domínguez-Villar M, Munoz-Suano A, Anaya-Baz B, Aguilar S, Novalbos JP, Giron JA, et al. Hepatitis $C$ virus core protein up-regulates anergy-related genes and a new set of genes, which affects T cell homeostasis. J Leukoc Biol. 2007:82:1301-10.

25. Kondo Y, Ninomiya M, Kimura O, Machida K, Funayama R, Nagashima T, et al. HCV infection enhances Th17 commitment, which could affect the pathogenesis of autoimmune diseases. PLoS One. 2014;9:e98521.

26. Kashyap M, Rochman Y, Spolski R, Samsel L, Leonard WJ. Thymic stromal lymphopoietin is produced by dendritic cells. J Immunol. 2011;187:1207-11.

27. Fernandez MI, Heuze ML, Martinez-Cingolani C, Volpe E, Donnadieu MH, Pie $M$, et al. The human cytokine TSLP triggers a cell-autonomous dendritic cell migration in confined environments. Blood. 2011:118:3862-9.

28. Fontenot $\mathrm{D}, \mathrm{He} \mathrm{H}$, Hanabuchi S, Nehete PN, Zhang M, Chang M, et al. TSLP production by epithelial cells exposed to immunodeficiency virus triggers DC-mediated mucosal infection of CD4+ T cells. Proc Natl Acad Sci U S A. 2009;106:16776-81

29. Dammacco F, Tucci FA, Lauletta G, Gatti P, De Re V, Conteduca V, et al. Pegylated interferon-alpha, ribavirin, and rituximab combined therapy of hepatitis C virus-related mixed cryoglobulinemia: a long-term study. Blood. 2010;116:343-53

30. Gauvreau GM, O'Byrne PM, Boulet LP, Wang Y, Cockcroft D, Bigler J, et al, Effects of an anti-TSLP antibody on allergen-induced asthmatic responses. N Engl J Med. 2014;370:2102-10.

31. Dammacco F, Sansonno D. Therapy for hepatitis $C$ virus-related cryoglobulinemic vasculitis. N Engl J Med. 2013:369:1035-45.

\section{Submit your next manuscript to BioMed Central and take full advantage of:}

- Convenient online submission

- Thorough peer review

- No space constraints or color figure charges

- Immediate publication on acceptance

- Inclusion in PubMed, CAS, Scopus and Google Scholar

- Research which is freely available for redistribution 